\title{
The Instrumental Value Arguments for National Self-Determination
}

In On Nationality, David Miller argues that,

National communities have a good claim to be politically self-determining. As far as possible, each nation should have its own set of political institutions which allow it to decide collectively those matters that are the primary concern of its members. This is sometimes phrased in terms of a right to national self-determination. ${ }^{1}$

In the literature, this thesis is known as the principle of national self-determination or the nationalist principle. It holds that, by virtue of sharing a national culture, a group has a prima facie right to self-determination. ${ }^{2}$

Supporters of the nationalist principle have proposed different arguments in its favor. ${ }^{3}$ Some argue that the equal treatment of different national cultures requires that we give each group the same rights, including the right to self-government. ${ }^{4}$ Others argue that national selfgovernment is inherently valuable, or that the intrinsic value of national identity and culture is sufficient to justify a prima facie right of a group to create its own state. ${ }^{5}$ Still others believe that

\footnotetext{
${ }^{1}$ Miller, 1995, 81.

2 The nationalist principle, when interpreted as a theory of secession, emphasizes a seceding group's status as a national community. It is different from other theories of secession that regard the sharing of a national culture as irrelevant to a group's right to secede, e.g. the just-cause or the plebiscitary theories. See Buchanan 1997; Norman 1998.

${ }^{3}$ A right to national self-determination can be understood in different contexts to mean different types of rights, claims, or entitlements. Sometimes the right is taken to mean more broadly a group's right to make decisions for itself by itself; other times it is taken to mean more narrowly the group's right to create its own sovereign state. In this paper, I focus on arguments supporting the latter type of right only. Thus, my argument does not affect a national group's other rights and entitlements (e.g., rights to cultural preservation or proportional representation). ${ }^{4}$ Supporters of the equality argument typically believe that a nation's right to self-government should take place at the sub-state level—namely, in the form of an autonomous government such as a city, a province, or a special administrative region. In the literature, these theories are called second-wave nationalism. See Kymlicka 1995; Norman 2006; Patten 2014; Schutter 2011.

${ }^{5}$ For arguments in favor of this claim, see Caney 1997; Margalit and Raz 1990; Miller 1995 Chapter 3; Nielsen 1997; Tamir 1993.
} 
national cultures are instrumentally valuable for the successful running of liberal democratic societies. Members of a national community typically possess qualities which are instrumentally valuable to the consolidation of important democratic institutions-e.g., mutual understanding, mutual trust, solidarity, reciprocity, etc. As such, national groups are considered ideal candidates for democratic states. These instrumental values of national identity buttress a national group's good claim to self-determination.

A full examination of the nationalist principle requires that we examine all arguments in its favor, including the arguments from equal treatment, the intrinsic value arguments, and the instrumental value arguments. One cannot complete such a daunting task in a single academic paper. Here, I will consider arguments of the last type only - the instrumental value argument. In particular, I focus on Miller's argument for national self-determination. ${ }^{6}$ According to Miller, national identity is indispensable for the successful functioning of a liberal democracy. In particular, national identity makes important contributions to important democratic institutions, including creating incentives for the fulfillment of civic duties, facilitating deliberative democracy, and consolidating representative democracy. Because Miller appeals to the instrumental value of national identity and culture, we can label these arguments instrumental value arguments.

Miller's argument for the nationalist principle is unique in that, while most proponents appeal to the intrinsic value of national identity and culture only, Miller also explores the instrumental values that national identities can add to liberal democratic institutions. Some might

\footnotetext{
${ }^{6}$ To be clear, Miller's argument includes two separate theses. The first holds that a national community should have its own state, and the second that a state should have its own national culture. In the literature on nationalism, the first thesis is called cultural nationalism and the second civic nationalism. Together they support Miller's argument for national selfdetermination. The nationalist principle considered here is equivalent to the cultural nationalist thesis. Miller, 1995, 82.
} 
wonder whether an intrinsic value argument would provide stronger support for the nationalist principle compared to an instrumental value argument, given that the value it appeals to is inherent and non-instrumental. However, the intrinsic value argument might have a more limited support; it enlists only those who affirm the intrinsic value of national identity, but not those who do not. In contrast, Miller's argument may gather wider support. Even if you do not appreciate the intrinsic value of national identity, Miller suggests that if you value social justice or democracy, you may still find national cultures valuable - for without them, a democratic institution cannot achieve its full potential or even function properly.

In this paper, I consider the instrumental values of national identity and assess whether these values are sufficient to justify a national community's right to self-determination. In section I, I summarize Miller's definition of national identity and culture and explain the demand of the nationalist principle. In section II, I consider the instrumental values of national identity and culture and critically evaluate the three instrumental value arguments - the civic duty argument, the deliberative democracy argument, and the representative democracy argument. In section III, I consider the argument structure that these instrumental value arguments share. The instrumental value argument is commonly accepted as a valid argument form for the justification of rights. However, I show that this argument form does not apply to cases in which the relevant core rights are not moral rights but institutional ones. I conclude that the instrumental value argument fails to justify the nationalist principle.

\section{National Culture and the Demand for Self-Determination i. National Culture}


Before considering Miller's arguments, I should clarify what a national community is and what is involved in the demand for national self-determination. Let me begin by briefly describing the five important features of a national community in Miller's theory. First, the existence of a national community relies on the convictions of its members. Member of a national community typically self-identify as such. Members of a national group believe that their group has certain good or bad qualities, and their beliefs may be true or false. Nevertheless, members believe that they belong together and wish to continue their life as a group. ${ }^{7}$ Second, national identity involves an identity that "embodies historical continuity." 7 Third, national identity is an active identity in that members of a national community typically do things and make decisions together to shape their shared national culture. Thus, one may be proud of a right-doing of her co-national, even when she does not know the right-doer in person. Likewise, one may feel ashamed of her society's history of wrong-doing, even though she has not personally taken an active part in this history. ${ }^{9}$ Fourth, national groups typically have a homeland where the identity of members was formed, developed, and evolved. Lastly, members of the same national culture typically share a set of cultural characteristics. Miller calls these characteristics a common public culture. ${ }^{10}$

In addition, Miller argues that the relationships among members of the same national community can be intrinsically valuable. For this reason, a person may owe special obligations or partiality toward her compatriots that she does not owe to noncompatriots. ${ }^{11}$

\footnotetext{
${ }^{7}$ Miller 1995, 22-23.

${ }^{8}$ Miller 1995, 24.

${ }^{9}$ Miller 1995, 24

${ }^{10}$ Miller 2005, 25.

${ }^{11}$ Miller 2005.
} 
Recently, political philosophers and theorists have debated the definition of a national culture. ${ }^{12}$ I cannot consider fully the soundness of Miller's definition in this essay. I shall instead assume that his definition is correct and go on to consider the soundness of his instrumental value arguments.

\section{ii. The Demand}

Now that we have some idea about what a national culture involves, let us go on to consider the demand involved in the nationalist principle. First, the principle of national self-determination holds that a national community should have the right to make decisions for itself by itself. This right is typically associated with the right of a national group to create its own sovereign state, because having a nation's own state gives the group the most control over its group affairs. However, creating a state is not the only way to realize a group's self-determination right. A national group can have substantive control over its collective affairs via different political institutions and in different degrees. For instance, a national group can also realize its selfdetermination right by creating non-state political institutions such as a sub-state autonomous government. ${ }^{13}$ In those cases, although the group does not have the right to control external affairs such as foreign relations or military policies, it still retains substantive control over the internal affairs of the national community.

Second, a group's self-determination right is not absolute, but can be outweighed by competing rights of other groups. ${ }^{14}$ This means that, a national community may create its own government, except when doing so will violate some important rights of others. This may happen, for instance, when the creation of a new nation state will violate the human rights of a minority

\footnotetext{
12 Booth 2013; Kymlicka 1995; Patten 2014; Yack 2012.

${ }^{13}$ Miller, 1995, 11, 99-104.

${ }^{14}$ Miller, 1995, 81, 104-5; 1996, 265.
} 
group or the same self-determination right of another group. In other words, a national group has a right to self-determination; if one believes that the group should not exercise its right, the burden is on her to explain why the group should not do so.

Now that we have some understanding of national groups and their demands, let us consider the instrumental value arguments for national self-determination.

\section{The Instrumental Values of National Identity}

The instrumental value arguments try to justify the right of a national community to create its own state by showing how a national culture or identity plays a crucial role in maintaining liberal democratic institutions. Because a national culture or identity can support many different liberal or democratic institutions, there can, in principle, be many different instrumental value arguments. For instance, Avishai Margalit and Joseph Raz consider the argument that creating an independent state is an important way for a national community to avoid persecution. ${ }^{15}$ Interestingly, they conclude that even persecution is not a sufficient reason for a group to claim the right to selfdetermination. Here, I will not consider the soundness of this argument. Even if it is sound, the argument applies only to nations being persecuted. My concern is with determining whether a national community as such has a right to establish an independent state. That is, I am interested in arguments that advocate the right of a national community to establish an independent state even if the community is not persecuted, discriminated against or treated unfairly by the state.

\section{i. The Civic Duty Argument}

The civic duty argument stems from a communitarian-nationalist critique of liberalism. It holds that a national community is a proper candidate for establishing an independent state because

\footnotetext{
${ }^{15}$ Margalit and Raz, 1990, 450-451.
} 
national identity and camaraderie provide the kind of incentives indispensable to enforcing vital civic duties in a liberal democracy.

Miller points out that, for a liberal democratic society to function well, the government needs its citizens to fulfill certain civic duties. For instance, an institution essential in a liberal society is a resource distribution system. Distributive justice may require that resources be transferred from richer populations (or areas) to poorer ones. In addition, to maintain the normal functioning of society, a liberal democracy will from time to time need its citizens to fulfill certain duties, such as paying taxes, serving on juries, or serving in the military. A successful liberal democracy depends not merely on the fairness of social institutions, but also on the willing cooperation of citizens to fulfill these civic duties.

Can we be sure that citizens will willingly comply and perform these duties? According to Miller, liberals cannot explain how or why citizens would willingly cooperate and fulfill these civic duties instead of free-riding. In a liberal society, individuals do not necessarily share feelings of camaraderie. In such a society, citizens are likely to see the demands of civic duties as burdens or even sacrifices.

This kind of mentality is especially widespread among those who perceive themselves as members of different national communities. Miller considers the example of the former Yugoslavia and questions how the government would be able to justifiably demand that rich Slovenes transfer their resources to Serbs, especially when each group felt that it was entitled to the resources owned or created by its own members. ${ }^{16}$ If Miller is right, we can imagine how

\footnotetext{
${ }^{16}$ Miller, 1995, 84.
} 
difficult it would be to maintain a smoothly running liberal democracy when citizens are not willing to fulfill their civic duties. ${ }^{17}$

Some may think that the problem is not particularly worrisome. To enforce the demands of justice, a government may use further legal sanctions or punishments to penalize disobedience and force citizens to comply. Citizens would be discouraged from noncompliance if doing so resulted in a punishment, especially a severe one. Where there is a lack of willing cooperation, a government can increase the severity of legal punishments to enforce the demands of civic duties. Thus, so long as a government can use legal punishments to solve the problem of noncompliance, one need not worry about citizens not fulfilling their civic duties.

This response to the communitarian-nationalist critique only pushes the question further backward. The effectiveness of legal punishments does not emerge from nowhere, but presupposes the willing cooperation of the relevant parties. That is, unless willing compliance or cooperation is already in place, increasing the severity of legal punishment cannot be effective. The problem of willing cooperation cannot be solved by another measure that also depends on willing cooperation. In other words, appealing to legal sanctions and punishments cannot solve the problem of noncompliance. Besides, the more a government relies on legal sanctions and punishments to enforce civic duties, the more resource it has to spend on the relevant institutions, and the more costly the enforcement of civic duties becomes. Legal punishments, even severe ones, do not guarantee a satisfactory degree of willing cooperation.

To be clear, Miller is not questioning whether a liberal can justify the fairness of the demands of civic duties. He is concerned that even if a liberal society could justify the fairness of its political

${ }^{17}$ In addition to distributive justice, some believe that cultural homogeneity also contributes to criminal justice. For instance, some criminologists attribute the low crime rate in Northern European societies to their cultural homogeneity, see Von Hofer 2003. 
institutions, it still would not receive the willing compliance of citizens. In that case, even if the relevant social institutions were just, they would not be effective because citizens would not be willing to comply. The liberal distributive justice system works only if citizens comply with the demands of justice. Unless (at least) most of the citizens are willing to cooperate, the relevant social institutions cannot fulfill their functions. Thus, for a liberal society to run smoothly, it also needs to ensure that its citizens would be likely to fulfill their civic duties.

How does a liberal society do that? What argument can a liberal government give to convince its citizens that they should pay taxes or serve in the army? What can a liberal say to a citizen who feels that the distributive system is burdensome or even unfavorable to her? According to Charles Taylor, it is not good enough to say that the liberal distributive justice system is just. ${ }^{18}$ Why should one care about justice if justice is burdensome or even requires a lot of sacrifice?

The problem is especially obvious in societies composed of different national communities. In a society where citizens belong to different national communities, the government would have a serious problem justifying the requisite duties and implementing the relevant social institutions. In the case considered by Miller, if the state borders were different — that is, if the Slovenes had a state of their own - they would not need to devote a part of their resources to support the welfare of the Serbs. It is not surprising that the Slovenes saw the transfer of resources to the Serbs as pure sacrifice. Miller believes that in such cases, we can be assured that citizens would not be likely to cooperate, the relevant social institutions would not perform satisfactorily, and as a result the political institutions would fail. How, then, can a government solve this problem and make liberal democracy work?

${ }^{18}$ Taylor, 1985, 213. 
According to Miller, citizens will willingly comply with the demands of civic duties only if they share a sense of reciprocity or mutual-trust. ${ }^{19}$ For instance, when resources are to be transferred from a richer to a poorer region, the richer citizens will comply willingly only if they feel a sense of reciprocity between them and the poorer region, or if citizens of the richer region trust that those of the poorer region would do the same for them in case the situation reverses. Without a sense of mutual trust or reciprocity, the demands of justice will be seen by the citizens as burdensome and the demands of civic duties will likely not be met.

This is where national identity can make a substantial contribution. To address the problem of willing cooperation, some nationalists, such as Miller and Taylor, argue that national feelings and ties may provide the right kind of motivation. As John Stuart Mill suggested:

A portion of mankind may be said to constitute a nationality, if they are united among themselves by common sympathies [italics added], which do not exist between them and any others - which make them cooperate with each other more willingly than with other people, desire to be under the same government, and desire that it should be government by themselves or a portion of themselves, exclusively. ${ }^{20}$

Mill's description seems to fit our observation of national communities in general. Members of the same national community usually share a strong sense of brotherhood or fraternity; they usually trust each other more and recognize that they have certain obligations towards one another. This sense of trust and obligation does not exist between them and non-members. National identity can thus motivate compliance with civic duties by telling us why we should comply with their demands. Thus, Miller concludes that:

Provided then, that we endorse ideals of social justice, and recognize that these take hold mainly within national communities, we have good reason for wanting the political systems that can realize these ideals to coincide with national boundaries. ${ }^{21}$

\footnotetext{
${ }^{19}$ Miller, 1995, 84.

${ }^{20}$ Mill, 1991, 427.

${ }^{21}$ Miller 1995, 85.
} 
In short, national identity, or what Mill calls "common sympathies" among members of the same national community, can help strengthen the willingness of citizens to comply with the demands of civic duties. However, this is the case only if these citizens are also members of the same national community. That is, citizens are more willing to comply with the demands of civic duties if the boundaries of the state correspond to the boundaries of the national community. Where citizens are not of the same national membership, the sense of identity and common sympathy may not exist. ${ }^{22}$ Therefore, if we care about the successful functioning of a liberal democracy, then for the sake of its efficient operation, we must recognize that a state composed of members of the same national community does a better job of consolidating its social institutions, as its citizens recognize their obligations of justice to one another and are more willing to comply with governmental policies and fulfill their civic duties. ${ }^{23}$ Therefore, we should recognize that a national community is a good candidate for establishing an independent state. ${ }^{24}$

Is this civic duty argument sound? Does it justify the right of a national community to establish an independent state?

I believe that it does not. To begin with, even though it is true that members of the same national community share the same culture and history, it is not clear whether this entails that they also share a sense of mutual trust or reciprocity. It may be true that, in most national communities, members share a sense of trust with each other. Nonetheless, it is not true that all national

\footnotetext{
${ }^{22}$ Miller 1995, 84.

${ }^{23}$ Miller 1995, 93.

${ }^{24}$ For detailed discussion on the difference between national feelings and civic virtues, see Putnam 1993. The author would like to thank an anonymous reviewer of the journal for this reference.
} 
communities are like that. Whether members of the same national community share a sense of trust or reciprocity is a contingent fact that can vary from one national community to another and perhaps also from one generation to another. Sharing the same history or culture does not guarantee a stronger sense of reciprocity or mutual trust. Therefore, even if mutual trust and reciprocity enhances a group's qualification for establishing an independent state, not all national communities would be proper candidates for establishing independent states.

Additionally, trust and reciprocity are both matters of degree. It is not clear to what extent these exist among members of the same national community. It may be true that compared with a non-member, a member of a national community is more willing to trust and reciprocate with another member. However, this does not mean that the trust or reciprocity amongst the members is unconditional or all-encompassing. We have to be careful about the kind of trust and reciprocity that exists among members of a national community and the kind that is necessary for the fulfillment of civic duties. Although both involve trust and reciprocity, they are distinct. The kind of trust and reciprocity members have for each other may concern issues about their ways of living or the national cultures of their community. However, the kind of trust and reciprocity necessary for civic duties is a different matter. Willing compliance with the demands of a government requires trust of the government, patriotism, and perhaps the belief that civic duties are, in the long term, beneficial for the individual. It is not clear how trust and reciprocity among members of the same national community can help strengthen any of these beliefs. It is possible for members of the same national community to be willing to trust and reciprocate with each other, while unwilling to trust their own political institutions. There are many possible reasons for this distrustful attitude, and some of them are rooted in national culture. For instance, there are some national communities that, throughout history, have never been effectively ruled by the law. To get things done, a person 
has to go through some kind of 'backdoor.' A member of this kind of national community may indeed trust another member of his national community. However, it is likely that he would distrust his own government, not to mention the fact that he would not be willing to fulfill the duties this government demanded of him.

In addition, even within a nation state, there can still be members who, for whatever reason, want to free-ride. Citizens may wish to enjoy the benefit of social cooperation without making any contribution. This problem of free-riding exists not only in multinational states, but also in nation states. It is not clear how identifying with a national community can solve the problem of freeriding, or how this identification can be transformed into patriotism or identification with a state government, which would presumably discourage free-riding. In short, national identity and patriotism are distinct. While it may be self-evident that patriotism can motivate citizens to comply with the demands of a government, it is not clear whether national identity can serve the same function. ${ }^{25}$

Most importantly, even if a group does demonstrate a strong sense of mutual trust and reciprocity, this does not mean that it is a good candidate for building an independent state. Consider other types of communities whose members demonstrate an even stronger sense of trust and reciprocity, for instance, the believers of a religion or the members of a particular clan. Members of these groups also demonstrate very strong senses of mutual trust and reciprocity, and are even willing to sacrifice their personal interests for the interest of the group they identify with. Does this mean that these groups are good candidate groups for establishing democratic states? Do they have the right to establish their own states? If we say 'no' to those cases, then it is not clear

\footnotetext{
${ }^{25}$ Studies have been done to evaluate whether national identity creates incentives for social justice; so far there is no consensus in the literature on how to interpret the resulting data. See Miller and Ali 2014.
} 
in virtue of what we can say 'yes' to the case of a national community. Commenting on Miller, Caney suggests, "we have no reason to accept his assumption that nationality is the only or best

form of trust." 26 The type of trust and reciprocity one is looking for concerns the fulfillment of civic duties. Many different communities demonstrate qualities such as mutual trust or fraternity. However, it is not clear if the trust engendered by these qualities is the kind of trust necessary for performing civic duties.

Thus, the civic duty argument does not justify the right of a national community to establish its own independent state. At best the argument suggests that, for political institutions to work effectively, a liberal government must try to find, or even form, some "common sympathies" among citizens. That is, a liberal society needs to encourage identification with the government or patriotism. This may justify certain nation-building policies, such as educational programs, that aim at forming common sympathies or patriotism among citizens. ${ }^{27}$ However, that members of a national community identify themselves as such does not entail that they demonstrate the kind of trust necessary for civic duty or that they have the right to create their own democratic state.

\section{ii. The Deliberative Democracy Argument}

The second instrumental value argument for the right of a national community to establish an independent state is the effectual democracy argument. This argument holds that a national community is the proper unit for establishing an independent state because it is the kind of group in which the ideals of democracy can best be realized. There are two aspects of democracy to which membership in a national community can make a substantive contribution-deliberative

\footnotetext{
${ }^{26}$ Caney, 1997, 357.

27 Moore, 2000, 185.
} 
democracy and representative democracy. I will begin with a discussion of how national membership can contribute to deliberative democracy.

Deliberative democracy essentially involves the collective deliberation of citizens working out resolutions concerning the public affairs of their society. According to Miller, deliberative democracy is "the ideal of a political community in which decisions are reached through an open and uncoerced discussion of the issue at stake where the aim of all participants is to arrive at an agreed judgment. ${ }^{28}$ Because citizens are likely to disagree with each other, a decision satisfying each participant may be difficult to obtain. To reach even a preliminary agreement by democratic deliberation, citizens need to be committed to communicating and collaborating with each other. Given the probability of disagreement, concessions and compromises may at times be necessary. According to Miller,

[To] the extent that we aspire to a form of democracy in which all citizens are at some level involved in discussion of public issues, we must look to the conditions under which citizens can respect one another's good faith in search for grounds of agreement [italics added]. ${ }^{29}$

That is, for deliberative democracy to be effectual, a society needs its citizens to be committed to working together. This can be achieved only if citizens are willing to follow the same rules of negotiation and make concession when necessary. ${ }^{30}$ Would citizens be willing to do that?

This, again, is a challenge not to the fairness, but to the efficacy, of a democratic institution. The concern is finding the basis of the commitment necessary for deliberative democracy. Why would citizens be motivated to engage in the protracted process of overcoming their differences in order to achieve compromises? According to Miller,

\footnotetext{
${ }^{28}$ Miller, 1995, 96.

${ }^{29}$ Miller, 1995, 98.

${ }^{30}$ Miller, 1995, 96-7.
} 
[O]nly a common nationality can provide the sense of solidarity that makes this possible. Sharing a national identity does not, of course, mean holding similar political views; but it does mean being committed to finding terms under which fellow-nationals can agree to live together. ${ }^{31}$

Members of the same national community usually recognize that they owe special obligations to one another. This could serve as the basis of the commitment necessary for deliberative democracy, as members of the same national community would be willing to work with one another to resolve the problems of their society through democratic deliberation.

Does the deliberative democracy argument justify the right of a national community to establish an independent state? First, it should be noted that several philosophers have challenged the ideal of deliberative democracy. For instance, Lynn Sanders suggests that the results of democratic deliberation tend to reaffirm the view of the dominant majority and replicate the status quo - when you let the people talk, they just reinforce one another's implicit or explicit biases, which is unfavorable to minority groups. ${ }^{32}$ Thus, one must be careful about the value of deliberative democracy.

Here, I will not consider the value of deliberative democracy. Although genuine deliberative democracy is difficult to achieve, it is nevertheless possible. The obstacles are formidable, but not insurmountable. What democratic states should do is to explore feasible methods of deliberation so that genuine democratic deliberation can be achieved.

In any case, the issue is whether national identity and culture can help contribute to deliberative democracy. ${ }^{33}$ For deliberative democracy to work, citizens must be committed to

\footnotetext{
${ }^{31}$ Miller, 1995, 98.

32 Sanders, 1997.

33 Iris Marion Young raises a similar challenge to the idea that shared/common understanding is necessary for deliberative democracy, see Young 2000: 41-2. The author would like to thank an anonymous reviewer for this pointer.
} 
working with one another to deliver solutions to the problems of their society. According to Miller, national identity makes democratic deliberation possible by providing the necessary incentives among citizens to communicate and compromise. Can the basis of this commitment be found in national identity?

Some philosophers argue that national communities are communities of obligations. They argue that national partiality, or the special obligations members of a national community have toward one another, is defensible at least to some extent. ${ }^{34}$ If their arguments are successful, and members of the same national community owe obligations to one another, then these obligations might be utilized to make a substantive contribution to deliberative democracy. Here, I cannot determine whether membership in a national community entails any special obligations, either toward other members or the community itself. The soundness of those claims requires a more detailed discussion than is possible here. Nevertheless, I would like to point out that even if such obligations exist, there is a distinction between the obligations one may owe her national community and the commitment necessary for democratic deliberation. Commitment to deliberative democracy essentially requires the belief that it is an activity worth engaging in, and perhaps also the belief that other participants are equally committed. It is not clear how identifying with a national community by itself can promote these beliefs.

A defender of the deliberative democracy argument may object that those who make this comment fail to see the obvious. She might argue that if we take a look at a national community engaged in a struggle for self-governance and listen carefully to the demands and aspirations of its members, we can see clearly that these are people who are willing and ready to make sacrifices to establish an independent state. These facts attest to their commitment to working with each other.

${ }^{34}$ Gilbert 1996; Hurka 1997; Miller 2005. 
Otherwise, why go through all the trouble - the demonstrations, the conflicts, or even the bloodshed? These seem to be very good proof of their commitment and readiness to collaborate with one another and establish their own state.

Still, even if a person is very zealous about his own national community, this does not mean that he would be equally committed to democratic deliberation. As I explained in the last section, national identity, or the commitment to one's national culture and community, is different from patriotism, or the commitment to one's government and its relevant political institutions. Even if members of the same national community trust one another, this does not mean that they will also trust the political institution established by members of their own community. Likewise, even if members of the same national community recognize certain obligations they have toward one another, this does not mean that this will enhance their commitment to the enterprise of deliberative democracy. We need to be careful about what exactly it is that a person identifies with or is committed to. It is not difficult for us to imagine a group of nationalists who are so eager to preserve their national culture and identity that they are willing to adopt any measure necessary for that purpose, including less democratic or even undemocratic ones. When a person puts her national identity on top of the list of the things she values, other considerations are at best of secondary importance. When this happens, one's identification with a national community may be detrimental to democratic deliberation.

In addition, there are other types of groups whose members demonstrate commitment and solidarity; but we do not think of them as good candidate groups for establishing democratic states. For example, think again of the case of religious communities. Thus, it seems that the commitment and solidarity of group members does not make a national community a good candidate for establishing independent states. Again, the kind of commitment and solidarity necessary concerns 
democratic deliberation, and so far nothing about a national community shows a clear bearing between the commitments of a national group and democratic deliberation. Thus, we have yet to see the instrumental value of national identity for the effectiveness of deliberative democracy.

\section{iii. The Representative Democracy Argument}

The third democratic value argument is the representative democracy argument. Democracy effectively involves either direct participation in the public affairs of a society, or in most cases where direct participation is not feasible, indirect representation in the government. For representatives to properly represent the interests of citizens, the citizens must be able to communicate with and trust these representatives, and the representatives must be able to understand and sympathize with the citizens they represent. How can we be sure that such trust and understanding exist between citizens and representatives? Under what circumstances would this relation be available?

Many believe that the ideal relationship between citizens and their representatives exists only between people who belong to the same national community. In Kymlicka's discussion of the right of a national community to special representation, he suggests that this right presupposes implausibly that "people can only be fully represented by someone who shares their gender, class, occupation, ethnicity, language, etc." ${ }^{35}$ Nevertheless, this assumption is at least prima facie justified. When a representative does not share the same national membership as the citizens she represents, the language barrier and cultural differences between them could substantially undermine her capacity to communicate and empathize with those whom she represents. In such a case, it is highly doubtful that she could properly represent their interests. In contrast, members of

${ }^{35}$ Kvmlicka, 1995, 18. 
the same national community, due to their shared language, history, and culture, are likely to be able to communicate with each other well, and therefore understand each other better.

In addition to shared language and cultural heritage, members of the same national community also share a set of common interests. There can be cases in which the interests of different national communities are in competition or even in conflict. Because members of the same national community share the same interest in the preservation of their national culture and identity, it seems rather sensible to assume that, under normal circumstances, a representative who is a member of the same national community would be more likely to advocate the interests of her national community than a representative who is not. Mill suggests that, "[t]he ideally perfect constitution of a public office is that in which the interest of the functionary is entirely coincident with his duty." 36 In addition, he also says

Free institutions are next to impossible in a country made up of different nationalities. Among a people without fellow-feeling, especially if they read and speak different languages, the united public opinion, necessary to the working of representative government, cannot exist. ${ }^{37}$

Therefore, it is in general more desirable that a representative and her constituents share the same national membership. National membership is a crucial qualification for a representative; even if it is not a sufficient condition for a good representative, it definitely is a necessary one.

This argument applies not only to the case of representatives, but also to any governmental official or public servant. To serve the people, a public servant needs similar capabilities to do her job satisfactorily — sympathy and understanding. Sharing the same language and culture definitely makes it easier for her to sympathize with and understand citizens, while not sharing them makes

\footnotetext{
${ }^{36}$ Mill, 1991, 228.

${ }^{37}$ Mill, 1991, 428.
} 
it more difficult for her to do her job. Thus, national membership is also an important qualification for public servants in general.

Likewise, it is in general better to have a government whose public servants share the same national membership as its citizens. If government officials shared the same national membership as citizens, not only can they do a better job serving the citizens, but they can also work together to preserve their common interest in national identity. Thus, a national community is a good candidate group for a state. It is the kind of community in which the ideals of representative democracy can best be realized.

If citizens need representatives who share their identity to represent their interests, why not just give each national group the right to special representation? Why should a national community also be granted the right to establish an independent state? A liberal society may grant special representation rights not only to national communities, but also to other types of groups, such as women or the handicapped, whose interests affect the whole community. Isn't the right to special representation enough? Why the right to build a state?

One crucial assumption in the representative democracy argument is the disadvantage inherent in minority status. Where a state is composed of multiple national communities, the interests of the communities will be in competition or even in conflict. This is unfavorable for members of the minority nation because in the competition for social resources, a minority nation is highly likely to be outvoted by the majority. It is in principle possible for them to never win such competitions. Therefore, because of the disadvantages inherent in being a minority group, it is always better, according to Miller, for a national community to establish its own state. ${ }^{38}$ If a national community could establish an independent state, this would best guarantee that it would

\footnotetext{
${ }^{38}$ Miller, 1996/2000.
} 
not be taken advantage of by other majority groups. It would also make it easier for members to protect their own interests, as it precludes the interference of non-members. Thus, national communities should be given the right to establish independent states.

Therefore, if we care about how well representative democracy works, and if we care about how well public servants serve their citizens, we have to acknowledge that it is better to have a state where citizens and public servants are of the same national membership. This ideal can best be realized if the border of a state corresponds to the border of a nation. Thus, a national community is a proper candidate for establishing an independent state, because it is the kind of community where the interests of citizens can best be protected.

Is the representative democracy argument sound? Does it justify the right of a national community to establish an independent state? In section i, I questioned the claim that members of the same national community necessarily trust each other. Does this mean that the democratic representation argument does not work, as trust does not necessarily exist among members of the same nation?

Not necessarily. The kind of trust we discussed in the civic duty argument is the trust that each citizen will fulfill her civic duty. On the other hand, the trust we have here is the trust that the representative will defend the interests of the people he represents. To the extent that a representative shares the same interests as those she represents, it seems sensible to trust this representative more than someone who does not. The problem of free-riding usually occurs because of competing or conflicting interests. Thus, the problem of free-riding may occur even within a national community. However, because members of the same national community share 
a set of common interests, there is at least one good reason to assume that, other things being equal, members of the same group will defend the same interests.

There can indeed be situations in which the interests of a person are in conflict with those of her national community. Still, barring the unusual examples of traitors, it seems sensible to assume that members of the same national community share an interest in the survival and flourishing of their culture. Their interests are in agreement at least to that extent.

The soundness of the representative democracy argument depends partly on the truth of the claim that co-nationals represent each other better than non-members. This assumption is not indubitable. Some may deny that co-nationals represent each other better; they may argue that the claim is based on the false assumption of national homogeneity and ignores the internal divergence among co-nationals. Still, I am willing to concede that, due to their shared interest in national membership, other things being equal, members of the same national community can represent each other better than representatives of a different national background. ${ }^{39}$ Does this entail the right to establish an independent state?

I believe that it does not. The idea underlying the representative democracy argument is that, when a group of people (1) share a set of common interests and (2) are minority group in society, the group should be given the right to establish an independent state so that they can escape the disadvantages of their minority status. However, there are groups which may meet both criteria but do not seem to be entitled to this right. Consider the case of gender identity. It is often assumed that a woman can better represent the interests of women. As a minority group, women face challenges and discrimination that men do not. Thus, being a woman is essential for sympathizing with the female experience and understanding how to protect women's interests. Thus, women

${ }^{39}$ Kymlicka, 1995, 138. 
should be represented by a woman. Moreover, being a minority is inherently disadvantageous. It is always better to be a member of the majority than the minority. Does this mean that women should be given the right to establish an independent state? I believe that most people would say no. There may be different reasons why people would say so, and an important one is that recognizing women's rights to create a state will inevitably encroach upon the rights of nonwomen. While it is important to protect women's rights and interests, giving women the right to create a state will convey on them the authority over a wide variety of public affairs. This allows the group to subject nonmembers to the rules they created and may be detrimental to the interest of nonmebers. Therefore, although it is important for public officials to share the same interests as the governed, a right to representation does not entail the right of a disadvantaged group to establish its own state.

Even though the representative democracy argument fails to justify the right of a national community to establish an independent state, it still teaches us a valuable lesson. As the example of gender identity illustrates, representative democracy requires a conformity of interests between the representatives and the represented. Thus, when a decision needs to be made regarding which group of people counts as one group and thus should be assigned a representative, we must take into consideration the interests people have. This may mean that decisions concerning administrative boundaries must take into account the national membership of the relevant population. In spite of these insights, the representative democracy argument fails to support a national community's right to create its own state.

In this section, I have shown that none of Miller's instrumental value arguments successfully justifies a national group's right to self-determination. One might wonder whether the reason for 
this failure has to do with the values Miller considered. Perhaps we have not found the right instrumental value. Perhaps there is some other instrumental value of a national culture that is sufficient to justify a right to national self-determination.

In the following section, I will explain why this strategy is not promising. The reason has to do with the argument structure of instrumental value arguments. These arguments try to justify a right by appealing to its instrumental value. While this strategy usually works very well for justifying various individual moral rights, it does not work in cases of institutional or group rights.

\section{Instrumental Value Arguments for Rights}

Instrumental value arguments support the right of a national community to establish an independent state by explaining how certain qualities of a national community could make instrumental contributions to important liberal democratic institutions. I have argued that even when we assume that national groups do have these qualities, such instrumental qualifications do not justify the rights to establish an independent state. Members of other types of groups demonstrate similar qualities; however, we do not think that these groups are therefore proper candidates for the right to self-determination.

A supporter of the democratic value argument may argue that this does not successfully refute the argument. He may suggest that the last claim in the previous paragraph is wrong. He may insist that any communities demonstrating these same qualities should also be given the right to establish an independent state. The lesson to be learned, then, is not that a national community does not have the right to establish an independent state, but that it is possible for other types of communities to have the same right if they demonstrate the relevant qualities. 
This may sound far-fetched, as there do not seem to be any actual examples. Still, a lack of an example does not refute a normative principle. Moreover, the supporter would remind us that the right is a prima facie right and may be overridden by other more important rights. This may explain why we do not see any examples of other types of communities exercising these rightsbecause the rights are overruled by those that are more fundamental. Nevertheless, this does not mean that these groups whose members demonstrate democratic qualities do not have a prima facie right. A prima facie right may be overridden by other more important rights, but this does not mean that there is no prima facie right.

It may be true that certain qualities are so important to liberal justice that the possession of them makes a group a good candidate for being an independent state. However, even being a good candidate does not justify a prima facie right. For instance, a person may have the qualities essential to being a good president. Nevertheless, this does not mean that he has a prima facie right to become president. He may have the right to participate in a fair presidential election; however, he does not have the right to be the president. ${ }^{40}$ No one is entitled to a right just because of his qualifications. Similarly, no group is entitled to a right just because of its qualifications.

The deeper problem with instrumental value arguments is that this is not how we think about instrumental values. There are various cases in which a moral agent could be of instrumental value to certain important institutions or fundamental values. However, even in those cases we do not think that the instrumental value by itself gives rise to any right, moral or legal. Instrumental qualifications do not justify rights. Thus, citing the instrumental value of national cultures to liberal democratic institutions cannot justify the right of a national community to establish an independent state.

\footnotetext{
${ }^{40}$ Rawls, 1999, 88.
} 
At this stage, one might wonder why the instrumental value arguments that typically work well to justify rights in other contexts fail to justify a group's right to national self-determination. Philosophers use instrumental value arguments all the time to derive various human or civic rights. The process typically goes like this. One begins by citing a self-evident premise. This typically involves specifying a core right $\mathrm{C}$ the value of which is self-sufficient, e.g. a right to life. One then tries to justify a derivative right $\mathrm{D}$ by explaining how this right to $\mathrm{D}$ is an important means to protect the core right $\mathrm{C} .{ }^{41}$ For instance, one may try to derive a right to use force in self-defense by appealing to the instrumental value it has to the protection of one's right to life. I have a right to life. If, under certain circumstances, using force is the only means to protect my life, then I must also have the right to use force to protect my life. I can use force in self-defense sometimes because this right contributes instrumentally to the protection of an important core right, i.e., my right to life. Or alternatively, consider the case of property rights. A person has property rights over her house. If building fences will help her protect her property, she must also have a right to build fences around her house. In this case, her right to build fences is derived from her right to private property. She has this right because it contributes instrumentally to the protection of her right to private property, which is a core right. We can see from these two examples that instrumental value arguments are useful in establishing the validity of certain rights. If instrumental value arguments work well in these cases, why then do they not work in the case of democratic arguments?

I think that the answer has to do with the core right from which one justifies the derivative right. The relationship between the core and the derivative right is justificatory - namely, the core right justifies the derivative right. For this chain of justification to work, the moral value of the core right must be self-standing and in need no further justification. In the two cases we considered

\footnotetext{
${ }^{41}$ Raz, 1996, 166.
} 
in the last paragraph, the core rights are the rights to life and property, which are both considered self-standing moral rights that need no further justification. One might argue that the right to property is not self-standing, but is derived from, say the right to life or liberty. At any rate, the conclusions of these arguments must rest ultimately on a non-derivative core right the value of which is self-evident. Can the instrumental value argument derive a national group's right to selfdetermination from a self-evident core right?

To do so, one must identify the core right with which one justifies the derivative right to self-determination. What would the core right be in this case? We can identify the core right by examining the means-ends reasoning involved in the democratic value arguments. In these arguments, the instrumental values appealed to are said to be means to the end of consolidating liberal or democratic institutions. Thus, for this argument to validly deduce a group's right to create a state, it must assume that the right-holder, namely, the national group, has the right to create a liberal democratic state. Only then can the instrumental value argument validly deduce a right of a national group to self-determination. Without this premise, the instrumental value of a national culture could not justify the right of a group to create its own state.

However, this assumption is problematic for several reasons. First, while it is commonly recognized that individuals have certain moral rights that do not require further justification — the right to life and the right to liberty—groups typically do not enjoy such rights. To be clear, groups may have rights; however, these rights are not self-evident but require justification. In addition, the core right stipulated in the democratic value arguments - namely, the right of a national group to create a liberal democratic state-is not a self-evident right but requires further justification. Given that this is not a self-evident premise, one must first try to justify this right on other grounds. Moreover, in the context of the instrumental value arguments, this premise is exactly the 
conclusion its proponents seek to prove. In other words, any instrumental value argument for national self-determination is inevitably circular. Unless we assume that a national group has a right to create a state, any instrumental value it adds to democratic institutions cannot justify its right to self-determination. Thus, it is useless to look for new instrumental values of a national culture.

Let us consider again the argument from avoiding persecution. This argument takes the form of an instrumental value argument. Margalit and Raz argue that persecution is neither necessary nor sufficient for the right of self-determination. Some may disagree, and I suspect that their reason is because they think that members of the group have rights to live, and this entails that they also have the right to adopt means that help them avoid persecution, especially when this is the only way for members to avoid death. I agree with Margalit and Raz that there are other ways to avoid persecution, but just for the sake of argument, let us assume that creating a nation state is the only way to avoid persecution Wouldn't this instrumental value argument justify the group's right to self-determination? Yes, it would. But notice that, in this case one is trying to derive a right from a core right, namely the right to life. If creating a state is the only way for members of a group to avoid persecution, then it seems that if members of the group have the right

to create a state because they have rights to life. However, this argument does not establish a general right to national self-determination, as it applies only to groups facing persecution.

\section{Objections}

In this section, I will consider two objections and try to respond to them.

\section{i. A Shared Culture is Essential for Real Democracy}


Some readers may find my conclusion counter-intuitive. Empirical evidence shows that a democratic culture is essential in consolidating democratic institutions. In many societies where a democratic culture is lacking, formal democratic institutions do not serve to protect the well-being of the demos. For instance, although there are democratic institutions in many Latin American and Southeast Asian states, populism seem to replace democracy. Citizens and elected officials equally see democratic institutions as a means of promoting private interests. Some hold prolonged protests after their preferred candidate loses an election. Others sabotage the legislature to prevent important bills from being passed only because they want to give their political enemy a hard time. Without a democratic culture, formal democracy cannot guarantee substantive democracy. ${ }^{42}$

I agree that a democratic culture is essential for a sound democracy. True democracy requires not merely formal institutions but also a shared democratic culture. Having formal democratic institutions - the right to vote and be elected or the right to freedom of expressiondoes not guarantee true democracy. In many societies, the development of democracy requires cultural change, not just the creation of formal institutions.

Nevertheless, it is important to note that, sharing a national culture is different from sharing a democratic culture. The fact that members of a national group share a culture does not guaranteed the soundness of the resulting democracy. The reason is that the character of a national culture may be such that it does not take democratic institutions seriously. Absolute loyalty to one's family or clan may be a valued feature in a national culture. If so, then not only does the national culture make no contribution to consolidate democracy, it actually causes harm to democratic institutions.

\section{ii. Qualifications Can Justify Rights}

${ }^{42}$ The author would like to thank an anonymous reviewer for raising this question. 
Some may wonder whether or not instrumental qualifications can sometimes justify rights. For instance, to win the right to child custody, a divorcing parent must demonstrate to the court her superior child-raring ability and prove that she is better qualified than her former spouse in serving the needs of their child. In other words, instrumental qualification plays an important role in the assignment of rights. ${ }^{43}$

Again, I do not deny that instrumental qualifications can sometimes be used to justify certain rights; what I deny is that they can justify a right without being combined with a selfevident core right. Here, I shall not consider in detail the differences between a parent's right to child custody and a nation's right to self-determination. Let me note briefly an important difference between the two. In cases of custodial rights, the right arises out of a minor's need to protect her core right to life, etc. Protecting the minor's right requires the provision of certain goods and services - food, shelter, education, guardianship. Presumably, both parents have a duty to protect this right. However, on occasion a divorce makes it necessary to assign only one parent as the primary bearer of this responsibility. Custodial right, if it is considered a right at all, involves a right to perform some existing duty. Given that custodial right exists because minors have needs, the court may make the decision by examining the qualification of relevant candidates. Further, notice that this right is not granted merely on the basis of qualification. A PhD in child development may have superior qualifications than the child's own parents, but the expert does not have a right to child custody just by virtue of her expertise.

In cases in which nations demand the right to self-determination, the basic needs and rights are not in question. Thus, instrumental qualifications cannot be used to justify a right to selfdetermination.

${ }^{43}$ The author would like to thank an anonymous reviewer for raising this question. 


\section{Conclusion}

In this paper, I have shown that there are several problems with Miller's instrumental value arguments. First, the assumptions that members of a national community have the relevant qualities - mutual trust, reciprocity, sympathy, and commitment to communication and compromise - are disputable. Second, even if members of a national community do demonstrate these qualities, it is not clear if and how these qualities can help to protect liberal democratic institutions, including the fulfillment of civic duties and consolidating deliberative and representative democracy. Third, even if a national community does demonstrate these qualities, and these qualities are indeed useful in consolidating these liberal democratic institutions, the instrumental value of these qualities still does not justify the right of a national community to create its own state. Therefore, the instrumental value arguments fail to justify the right to national self-determination.

\section{Reference}

Booth, W. James

2013 "Maîtres Chez Nous: Some Questions about Culture and Continuity—A Response to Alan Patten's Rethinking Culture: The Social Lineage Account," American Political Science Review 107(4): 866-874.

Buchanan, Allen

1997 “Theories of Secession”, Philosophy and Public Affairs, Vol. 26, No.1, Winter, 1997, pp.31-61.

Caney, Simon 
1997 "Self-Government and Secession: The Case of Nations," The Journal of Political Philosophy 5(4): 351-372.

De Schutter, Helder

2011 “Federalism as Fairness,” The Journal of Political Philosophy 19(2): 167-189.

Gilbert, Paul

1996 “National Obligations: Political, Cultural or Societal?" in National Rights, International Obligations, edited by Simon Caney, David George, and Peter Jones, US: Westview Press, 102-118.

Hurka, Thomas

1997 "The Justification of National Partiality," in The Morality of Nationalism, edited by Robert McKim and Jeff McMahan, NY: Oxford University, 139-157.

Kymlicka, Will

1995 Multicultural Citizenship, Oxford University Press.

Margalit, Avishai and Joseph Raz

1990 “National Self-determination,” Journal of Philosophy, 87(9): 439-461.

Mill, John Stewart

1991 Considerations on Representative Government. On Liberty and Other Essays, NY: Oxford University Press.

Miller, David

1995 On Nationality, NY: Oxford University Press

Miller, David

1996 "Secession and the Principle of Nationality," in Rethinking Nationalism, edited by Jocelyne Couture, Kai Nielsen, and Michel Seymour, Canadian Journal of 
Philosophy Supplementary Volume 22, : 272. Calgary: University of Calgary

Press, second printing 2000.

Miller, David

2005 "Reasonable Partiality Towards Compatriots," Ethical Theory and Moral Practice 8: 63-81.

Miller, David, and Ali, Sundas

2014 “Testing the National Identity Argument," European Political Science Review 6 (2): 237-59.

Moore, Margaret

2000 "Nationalist Arguments, Ambivalent Conclusions," in Nationalism and Ethnic Conflict, edited by Nenad Miscevic, Open Court, 177-196.

Nielsen, Kai.

1997 "Cultural Nationalism, Neither Ethnic nor Civic," The Philosophical Forum, 28(1-2): 42-52.

Nielsen, Kai

1998 "Liberal Nationalism and Secession," in National Self-Determination and Secession, edited by Margaret Moore, NY: Oxford University Press, 103-133.

Norman, Wayne

1998 "The Ethics of Secession as the Regulation of Secessionist Politics," in National Self-Determination and Secession, Margaret Moore (ed), New York: Oxford University Press: 34-61.

2006 Negotiating Nationalism-Nation-building, Federalism, and Secession in the Multinational State, NY: Oxford University Press. 
Patten, Alan

2014 Equal Recognition: The Moral Foundations of Minority Rights, New Jersey: Princeton University Press.

Putnam, Robert

1993 Making Democracy Work: Civic Traditions in Modern Italy, Princeton, NJ:

Princeton University Press.

Raz, Joseph

1986 The Morality of Freedom, New York, NY: Oxford University Press, reprinted 2009.

Rawls, John

1971 A Theory of Justice, Harvard University Press, reprinted 1999.

Sanders, Lynn

1997 “Against Deliberation,” Political Theory (25:3): 347-377.

Tamir, Yael

1993 Liberal Nationalism, New Jersey: Princeton University Press.

Taylor, Charles

1986 “Alternative Futures: Legitimacy, Identity, and Alienation in Late Twentieth Century Canada," in Constitutionalism, Citizenship and Society in Canada, edited by Alan C. Cairns and Cynthia Williams, Toronto: University of Toronto Press, 183-229.

Von Hofer, Hanns 
2003 "Prison Populations as Political Constructs: The Case of Finland, Holland and Sweden," Journal for Scandinavian Studies in Criminology and Crime Prevention 4(1): 21-38.

Yack, Bernard

2012 Nationalism and the Moral Psychology of Community, Chicago: The University of Chicago Press.

Young, Iris Marion

2000 Inclusion and Democracy, NY: Oxford University Press. 